\title{
Morphology Of SBS-Modified Asphalt Using Low Vacuum SEM
}

I. Puente-Lee *, P. S. Schabes-Retchkiman**, J. Rojas-García.***, L. Ríos-Guerrero***, and R. Herrera-Nájera.*

* Departamento de polímeros L-213, Facultad de Química, U.N.A.M., México

**Instituto de Física, UNAM, AP 20-364, México DF 01000

*** CID Centro de Investigación y Desarrollo Tecnológico - GIRSA S. A. de C.V.

Development of asphalt modification has been increased because of the need to have asphalt cements with better properties[1]. At low temperatures, asphalt is brittle and at high temperatures it flows. . Modification yields: a) reduction of thermal sensitivity, b) better sensitivity on loading time, c) better deformation strength, and d) better tension and fatigue strength.

The styrene-butadiene-styrene (SBS), styrene-isoprene-styrene (SIS), EPDM, atactic polypropylene (APP), ethyl vinyl acetate (EVA) have been used as modification agents in asphalt binders[2,3]. Fluorescence microscopy is much often used in asphalt morphology characterization, although the results are usually poor. The purpose of this paper is to define a simple technique to elucidate morphologies from polymer - modified asphalts using scanning electron microscopy.

An asphalt AC-20 Salamanca from Mexico was taken as the asphalt neat. The SBS - modified asphalt was prepared at $180^{\circ} \mathrm{C}, 2500$ r.p.m. and 30 minutes in a Ross mixer. Modified asphalt was prepared with $12 \%$ by weight of a triblock Styrene-Butadiene-Styrene. The polymer modified asphalt sample was frozen with liquid nitrogen and then it was fractured. A crosssection area of sample was taken and mounted on an aluminum SEM specimen stub. The sample was stained by exposure to the vapor of an aqueous $1 \% \mathrm{OsO}_{4}$ solution overnight at room temperature. Micrographs were obtained using a JEOL JSM-5900 LV-SEM. Low vacuum mode and backscattered electron signal were used. Optical microscopy was performed in a microscope Olympus - Continuum using the fluorescence BX-FLA mode with a blue filter.

Figure 1 shows a typical fluorescence microscopy image 1t shows the morphology from SBS modified asphalts. Light regions are rubber which are compatible with the maltenic fraction of asphalt and dark regions are asphaltenic fraction incompatible with polymer. Figure 2 shows an SEM image of the SBS-modified asphalt morphology stained with $\mathrm{OsO}_{4}$. Itis clear that SEM gave better contrast, magnification and resolution than fluorescence microscopy. Light regions correspond to the rubber phase and dark regions to the asphalt phase. It is convenient to notice that the morphology of SBS-modified asphalt has been found. It can be divided in three different phases: a SBS-rich phase figure $2 \mathrm{a}, \mathrm{b}$ and $\mathrm{c}$ ), an asphaltenic phase figure $2 \mathrm{a}, \mathrm{b}$ and $\mathrm{c}$ ) but also a third phase is present. That third phase shows semi-compatibility between asphaltenes and polymer compounds. This is shown in figure $2 \mathrm{~b}$ and $2 \mathrm{c}$ as gray and diffuse regions.

It has been established that the $\mathrm{OsO}_{4}$ staining and backscattered electron signal in SEM-LV yielded better resolution and more details of SBS-modified asphalts than fluorescence microscopy. SEM made possible to detect three different phases in modified asphalt: a polymerrich region, a semi-compatible region and no - compatible region or asphaltenic phase. 


\section{References}

[1] B. B. Brûlé et al., Proceedings of the association of asphalt paving technologists 1988, 57, pp. 41-64

[2] J. H. Collins and W.J Mikols,, Proceedings of the association of asphalt paving technologists 1985, 54, pp. 1-17

[3] G. N. King et al., Proceedings of the association of asphalt paving technologists 1986, 55, pp. 519-540

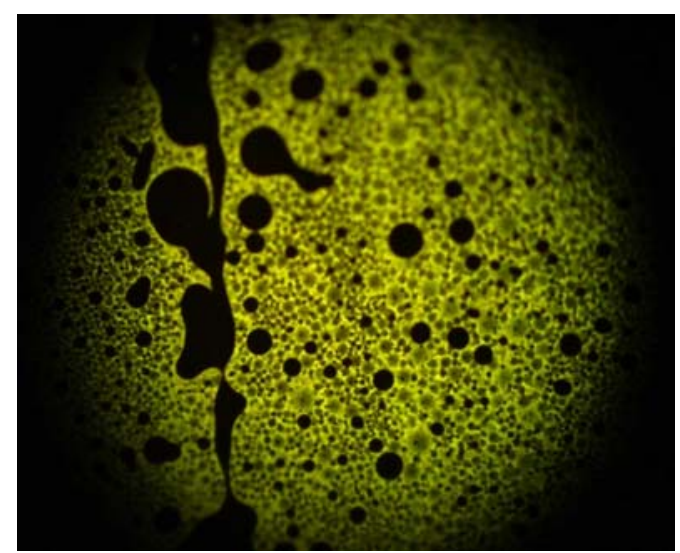

Figure 1. Fluorescence micrograph of the SBS - modified asphalt

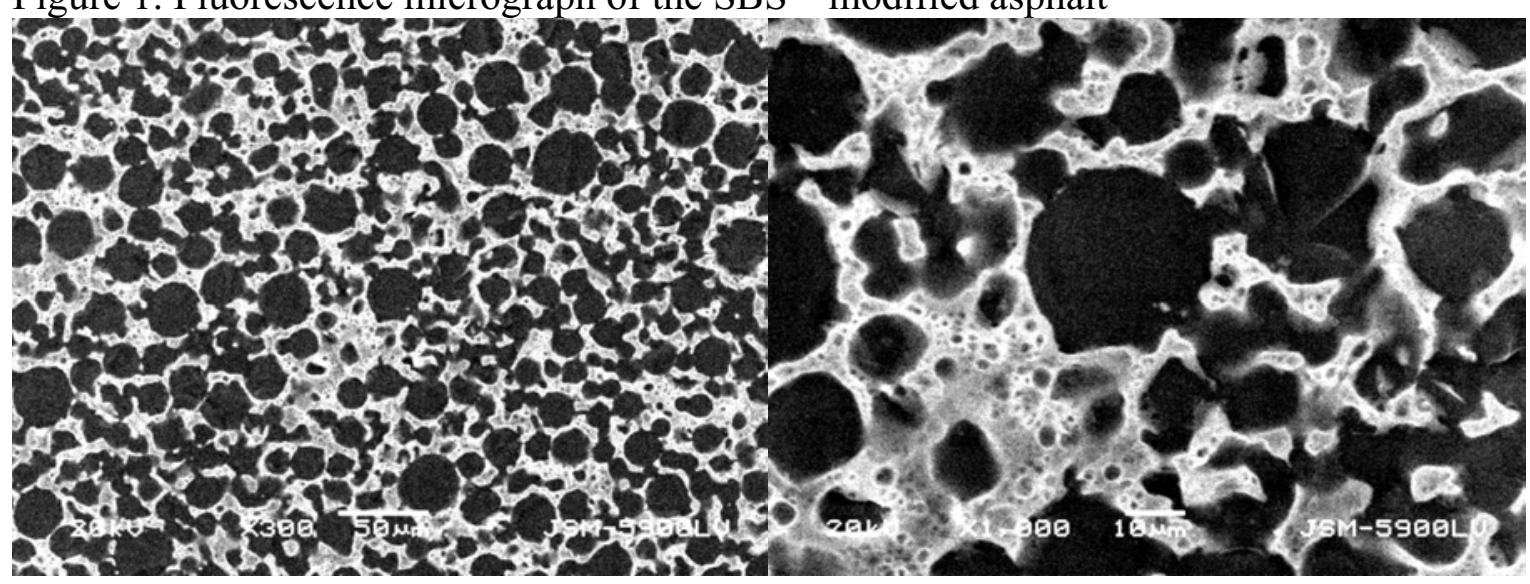

a)

b)

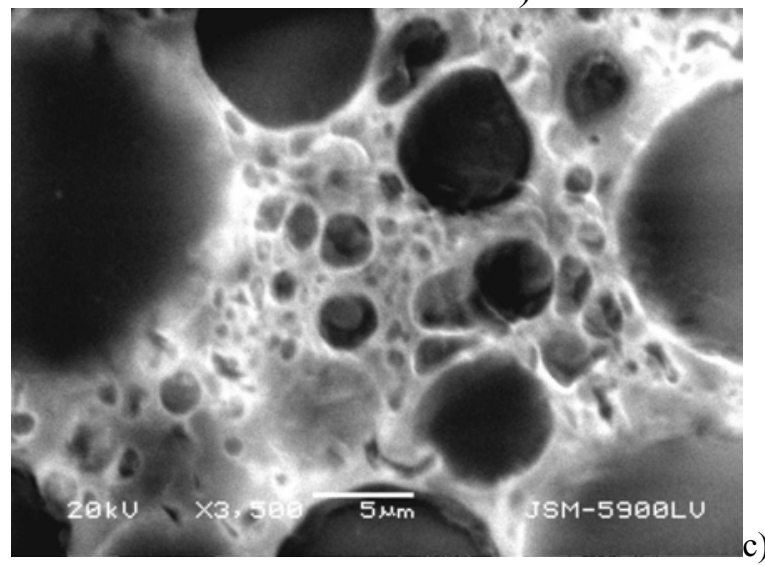

Figure 2. SEM micrographs of $\mathrm{OsO}_{4}$ stained $\mathrm{SBS}$ - modified asphalt. 